\title{
28 Research Suare \\ Evaluation of Antibiotic Residue in Cow Milk and Its Impact on Danio Rerio
}

\section{Jayanta Chowdhury}

Techno India University

\section{Riya Mukherjee}

University of Kalyani

Debanjan Dutta

University of Kalyani

\section{Tapan Kumar Mandal}

West Bengal University of Animal and Fishery Sciences

\section{Tarakdas Basu}

University of Kalyani

Sandhimita Mondal ( $\nabla$ sandhimita@gmail.com )

TIU: Techno India University https://orcid.org/0000-0002-6639-3367

\section{Research Article}

Keywords: Ceftriaxone, residue, zebra fish, developmental toxicity, genotoxicity, HPLC

Posted Date: July 6th, 2021

DOl: https://doi.org/10.21203/rs.3.rs-660593/v1

License: (c) (1) This work is licensed under a Creative Commons Attribution 4.0 International License.

Read Full License 


\section{Abstract}

Ceftriaxone (CEFT), a widely used wide-spectrum beta -lactam cephalosporin antibiotic, is used to treat bovine mastitis, which is caused by a variety of bacteria. When this antibiotic is used injudiciously, it leaves a residue that persists after pasteurization. Antibiotic residue contamination occurs when antibiotic residue exceeds its Maximum Residue Limits (MRLs). This has a negative impact on both public health and the environment. The aim of a recent study was to determine the concentration of ceftriaxone residue (CEFTR) in raw and pasteurized mastitis cow milk, as well as its role in developmental toxicity and genotoxicity in zebra fish model. CEFTR concentrations in raw and pasteurized milk were several times higher than CEFT's MRL. CEFTR showed a decrease in body length and yolk sac region of zebra fish larvae 7-amino cephalosporanic acid (7-ACA), C3 and C7 are the cephalosporin constituents that produced by the breakdown of CEFT that may present in CEFTR, have an impact on the zebra fish embryo in this stage of development. Comet Assay or single cell gel electrophoresis (SCGE) also exhibited highest percentage of tail DNA, and tail moment that is the ultimate indicator of DNA damage by breaking DNA strands and incorporating guanine residue in the genome that ultimately damages DNA. As a result, the CEFTR is extremely concerning for public health and the environment. The toxic effects of the CEFTR in zebra fish model have not been studied yet. This is the first comprehensive study.

\section{Introduction}

Mastitis is a chronic, economically important inflammatory disease that affects the dairy industry around the world. Bovine mastitis costs India a significant amount of money per year. Mastitis is caused by a variety of bacteria that are extremely susceptible to ceftriaxone. (Bhat et al. 2017). Ceftriaxone (CEFT) is a broad-spectrum, third-generation cephalosporin antibiotic with a beta -lactam structure. Because of its low toxicity, it is commonly used in bacterial infections such as meningitis, pneumonia, diarrhoea, joint infections, sepsis, and nosocomial infections(Sonda et al. 2019). Antibiotics including cephalosporins have active pharmaceutical ingredients (API) that have a harmful impact on the environment. It acts as a emerging contaminants (Das et al. 2019).

Antibiotics are manufactured in approximately 248,000 tonnes each year, with 48 percent of them being used to prevent and treat bacterial infectious diseases in humans and animals, according to the findings. 52 percent are used as a growth promoter in agriculture. (Ying et al. 2017). These are therapeutically administered to livestock to treat bacterial infections. These are also used as a subtherapeutic for disease prevention, growth promotion, and mortality reduction by lowering immune system function. These strategies help to minimize waste and toxin production (Ray et al. 2014);(Elizalde-Velázquez et al. 2016); (Graham et al. 2007); (Nisha 2008). Various antibiotics have stable structures and have harmful toxic effect and due to which non-biodegradable parts of such antibiotics are directly discharged into a variety of environmental compartments which leads to health hazards to human. Antibiotic use is huge, despite the lack of official survey data on the detailed use of various types of antibiotics (Feng et al. 2020). 
Excessive use of these antibiotics results in the presence of residual forms in the milk. Antibiotics are contained in various organ tissues, secreted in milk, foods, and eggs after excretion, and excreted in feces and urine (Ray et al. 2014); (Sachi et al. 2019). Among them, The duration and severity of exposure of antibiotic like, ceftriaxone have a significant effect on bla $a_{\mathrm{CTX}-\mathrm{M}}$ resistance gene amplification in the gut flora and it leads antibiotic antibiotic resistance, which is the major causes significant health care hazards (Sileshi et al. 2016); (Meletiadis et al. 2017). Cephalosporrin antibiotic contamination has a strong negative impact on human health and ecosystem as it waste water contain toxic substances(Das et al. 2019). This pollution has an effect on marine ecosystems, halting ecosystem and organism functions during their life cycle (Kraemer et al. 2019). Antibiotic residues in river water influence water quality and vary seasonally as a result of antibiotic runoff (Diwan et al. 2018).

Antibiotics are widely used in the treatment of animal diseases, as well as a growth promoter and since 2006, European Union (EU) legislation has prohibited the use of antibiotics as a growth enhancer (CháferPericás et al. 2010).

Antibiotic residues from human and animal sources are carried into many water bodies, posing a health risk to humans (Zhao et al. 2018). Drug metabolites have carcinogenic and mutagenic properties, as well as a negative impact on the various processes of human body (Nisha 2008). Antibiotic residues have now become a global problem (Teuber 2001). Antibiotics have slowed the growth of starter cultures used to make fermented milk products (Seymour et al. 1988). Humans are the ultimate consumers of antibiotic residue-containing products (Nisha 2008). The pasteurization process removes bacterial load from milk, but it is unable to reduce drug residue levels (Ruegg 2017). As a result, maintaining the quality of milk necessitates the monitoring of antibiotic residue levels in the milk. As a result, regulatory agencies have established the higher limit for a variety of anti-infective agents which is known as the Maximum Residue Limits (MRLs) (Beyene 2015). The main component of Cephalosporin wastewater is intermediate residues, which produce the fewest unrecycled materials, the majority of which are heterocyclic macromolecular compounds. Water containing a variety of toxic organic compounds can pose a threat to the organisms reside in the environment (Das et al. 2019).

The zebrafish embryo is a common model for mechanism-based research (Nishimura et al. 2016). Globally, an estimated $50 \%$ of all antimicrobials serve veterinary purposes. Bacteria that inevitably develop antibiotic resistance in animals comprise food-borne pathogens, opportunistic pathogens and commensal bacteria. The same antibiotic resistance genes and gene transfer mechanisms can be found in the microfloras of animals and humans. Direct contact, food and water contaminate animal and human habitats. It is reported that, resistant bacteria are accumulated by the use of antibiotics in agriculture and veterinary medicine which spread via agriculture and direct contamination (Teuber 2001). Antibiotics affect a variety of biomarkers in zebra fish (Oliveira et al. 2013). Tetracycline causes oxidative stress in zebrafish embryos, which slows development (Zhang et al. 2015). Some pesticides are genotoxic, and they have an effect on zebra fish (D'Costa et al. 2018) also. 
The goals of this study are (i) to quantify CEFTR in raw and pasteurized milk, (ii) investigate developmental toxicity of CEFTR in zebra fish, and (iii) investigate its role in DNA damage.

\section{Materials And Methods}

\section{Chemicals and reagents:}

SRL laboratories provided the analytical grade solvents used in the HPLC (India). Milli Q Elix (USA) filtered water was used. The analytical grade Ceftriaxone (CEFT) was also purchased from Sigma Aldrich (USA).

\section{Collection of milk samples}

40 milk samples (100ml / sample) were collected from cows in about 10 herds in the dairy farming villages around Kalyani, Nadia, West Bengal, India, after assessing the udder health of cows with a history of clinical and subclinical mastitis (i.e. 20 from clinical mastitis milk and 20 from subclinical mastitis milk). The mastitis milk samples were validated by the California Mastitis Test (CMT) (Mpatswenumugabo et al. 2017). The herds were labeled on the day of the first screening, and 30 days later, anamnesis of the treatment regime was obtained from the owners of those identified herds, and samples were collected and stored in sterile containers at $4{ }^{\circ} \mathrm{C}$ for future use. The Institutional Animal Ethics Committee of WBUAFS, Kolkata [Ref. No. IAEC/67 / xiv(B)] authorized the collection of milk samples and experimental procedures described in this manuscript on August 19, 2019, following the guidelines of the Committee for the Purpose of Control and Supervision of Experiments on Animals (CPCSEA), India. This research did not include any animal testing.As a result, in this study no animals were killed or anaesthetized.

\section{Ceftriaxone residue (CEFTR) screening and quantification in milk samples}

To detect CEFTR in raw milk samples, all samples were run through a High Performance Liquid Chromatography (HPLC) device (Schimadzu LC-20 AT system attached to Thermo ODS Hypersil C18 column ( $250 \mathrm{~mm}, 4.6 \mathrm{~mm}$-ID; $5 \mu \mathrm{m}$ particle size, USA) according to the standard protocol (Schenck and Callery 1998). For the study of CEFT residues in milk samples, the simple and responsive HPLC method was optimized and validated (Ibrahim and Nasr 2014). Pasteurization was carried out on all of them. For the residue, milk samples were subjected to HPLC in the same process. The light at a wavelength of 254 nm was detected using a UV Vis SPD 20 detector. The mobile method consisted of acetonitrile and milipore purified water after filtration and sonication. Comparing the curves obtained from experiments to the normal curve to examine the results. HPLC was used to separate drug residue from $20 \mu \mathrm{l}$ of processed milk samples abiding a standard protocol by utilizing "LC Real Time Analysis" software. The CEFTR quantification was done by comparing the peak area of the sample with that of the standard CEFT having the corresponding chromatogram (Kurjogi et al. 2019).

\section{Outcome of CEFTR on Zebrafish (Danio rerio)}

\section{Maximum Residual Limit (MRL) determination of samples for the in vivo study}


To standardize the process, drug residue aliquots were obtained in acetonitrile, and the multiples of the Maximum Residual Limit (MRL) in each sample were determined. Observed multiples of MRL of Ceftriaxone Residue in $1 \mathrm{ml}$ sample container, which is calculated in this manner, i.e., $141 \mathrm{X} \mathrm{MRL}$ in $1 \mathrm{ml}$ i.e., $1000 \mu$ l. So, $141 \mathrm{X}$ MRL $=1000 \mu$ i.e., $1 \mathrm{XMRL}=7 \mu \mathrm{l}$ (approx.) of Ceftriaxone residue. So, $7 \mu$ contain $0.1 \mathrm{ppm}$ (As, MRL of CEFT is $0.1 \mathrm{ppm}$ ).

Therefore, we inoculate the drug residue fraction collected from HPLC in $1 \mathrm{ml}$ of E3 medium containing 10 nos. of just hatched $24 \mathrm{hpf}$ zebra fish larvae at 25 well plate to check their livability under $1 \mathrm{xMRL}$ inoculums for $24 \mathrm{~h}$ in case of ceftriaxone Residue (CEFTR). We did same for acetonitrile also as drug residue dissolved in the acetonitrile.

In this study, we got tolerance to acetonitrile upto $20 \mu$ l. Liveability of Ceftriaxone Residue treated just hatched zebrafish larvae was checked under $1 X$ MRL to $3 X M R L$, i.e., the amount of that subjected drug residue is $7 \mu \mathrm{l}$ to $21 \mu \mathrm{l}$. It was observed that from 3x MRL of the drug maximum larvae was died.So, tolerance observed for Ceftriaxone residue is upto $2 \times \mathrm{MRL}$, that means $14 \mu \mathrm{l}$.

Therefore, just hatched and survived zebra fish larvae in $1 \mathrm{ml}$ E3 medium was charged with $14 \mu \mathrm{l}$ of Ceftriaxone residue i.e $0.2 \mathrm{ppm}$. CEFTR present $0.2 \mathrm{ppm}$ in the E3 medium and concentration of same pure drug was also charged in E3 medium containing the same quantity of zebra fish larva and $20 \mu$ of acetonitrile was also charged in E3 medium containing the same quantity of larvae. Untreated larvae at E3 medium is acting as control.

Zebra fish eggs were maintained and hatched by the following modified method reported by Oliviera et al., 2013 (Oliveira et al. 2013) (Chowdhury et al. 2020).

\section{Role of CEFTR on morphological traits of of Zebra fish embryo}

For the experiment, $48 \mathrm{hpf}$ zebrafish embryos were used. The effects of CEFT, CEFTR, and ACTN on the developmental process of $48 \mathrm{hpf}$ embryos for 24 hours were investigated. The characteristics that were measured were body length, yolk sack length, and yolk sac height. Using an EVOS FL Auto fluorescence microscope(Invitrogen), these traits were measured for at $72 \mathrm{hpf}$ of each zebrafish. The temperature was held at $28^{\circ} \mathrm{C}$ (Zhang et al. 2015). Image J 2.0 software was used to examine the larva..

\section{Role of CEFTR on DNA damage of Zebra fish embryo}

The Comet Assay, also known as single cell gel electrophoresis (SCGE), is a sensitive and fast technique used in DNA damage, repair, genotoxicity testing, and genotoxicity evaluation (Ostling and Johanson 1984);(Singh et al. 1988).

Cell samples, including controls, were prepared by centrifuging trypsin-treated cells from $24 \mathrm{hpf}$ zebra fish embryo for this test. For 24 hours, zebra fish embryos were exposed to $2 X$ MRL CeftriaxoneR (CEFTR) drug residue, i.e. $14 \mu \mathrm{l}, 20 \mu \mathrm{l}$ Acetonitrile (ACTN), and $14 \mu \mathrm{l}$ pure Ceftriaxone (CEFT). The cells were then 
processed and dyed according to the standard protocol. (Frenzilli et al. 2004); Olive and Durand, 2005; Speit and Rothfuss, 2012).

Cometscore 2.0.0.0 software was used to analyze the comet sample, which was done one by one.

For the detection of DNA damage, the percentage of tail DNA and DNA migration (tail moment) were calculated (D'Costa et al. 2018)(Rocco et al. 2012).

The sample size was sufficient for statistical data analysis to estimate DNA damage caused by the stated treatment using the experimental model chosen.

\section{Results}

\section{Detection and quantification of CEFTR by HPLC}

CEFTR was detected in raw and pasteurized milk samples (Fig.1), which was verified by comparing the peak of the CEFT standard drugs in the HPLC result.

CEFTR concentrations were $1.75 \pm 0.44$ and $0.56 \pm 0.03 \mathrm{ppm}$, respectively, in raw and pasteurized milk samples (Fig.1). CEFTR levels in raw and pasteurized mastitis milk were found to be approximately 17.5 and 5.6 times higher than MRL in this recent report, which is very alarming.

\section{Morphological traits}

CEFTR showed detrimental effects on the growth and development of zebrafish after the treatment. These treatments reduced body length (Fig.2b, 2c, 2d and 3a) while compared with the untreated group (Fig.2a, 3a). The CEFTR treated shows shortest yolk sac length $430.2 \pm 28.94 \mu \mathrm{m}$ and yolk sack height $72.33 \pm 3.84$, and shorter body length $1489 \pm 38.44 \mu \mathrm{m}$ (Fig.2c,3b, 3c, 3a). The growth of the body length of the embryos was measured at $72 \mathrm{hpf}$ and the results are shown in Figs. 2a,2b,2c,2d and $3 \mathrm{a}$ and the yolk sack length and height are shown in Fig.3b and 3c. CEFT and acetonitrile do not affect significantly on body length compared to the controls. But CEFTR has the detrimental effect on the growth of the embryo of zebra fish.

\section{DNA damage}

CEFTR demonstrated developmental toxicity in this study. This residue also checks for DNA damage in individuals. This was measured by \% tail DNA and DNA migration (tail moment) .

CEFT treated cell shows $23.45 \pm 0.59 \%$ tail DNA. No damage in the untreated group (Fig.4a). ACTN treatment exhibits $13.93 \pm 0.64 \%$ tail DNA while CEFTR treated showed highest $65.95 \pm 0.78 \%$ tail DNA (Fig.4a) after only $24 \mathrm{~h}$ treatment. Tail moment is significant i.e.0.58 in CEFTR respect to ACTN treated and CEFT treated samples, where tail moment were 0.20 and 0.27 respectively(Fig. 4b).With its high sensitivity, the Comet assay detects early DNA damage. 


\section{Discussion}

In veterinary medicine, antibiotics are often used to treat infectious diseases such as mastitis. (Aalipour et al. 2015). Ceftriaxone (CEFT) residue was found in thirty out of forty samples. As a result, CEFTR was our main priority for drug residue. According to previous report, Tetracycline residue was not fully removed from milk at $70^{0} \mathrm{C}$, depending on milk product matrix and its properties (Kurjogi et al., 2019). Ceftriaxone has a maximum residue level (MRL) of $0.1 \mathrm{ppm}$ in milk, according to European Commission regulation 2377/90/EC (Sachi et al. 2019). Antibiotic residues in milk and milk products that exceed the MRL cause significant health issues for consumers(Van den Meersche et al. 2016). Antibiotic residues in food have a negative impact on health and lead to the emergence of antibiotic resistance genes (Hassan 2014). After initial degradation, ceftriaxone produces some intermediate products. This intermediate was then broken down further into small molecules (Zhao et al. 2018).

In our current study, CEFTR has the detrimental effect on the growth of the embryo of zebra fish. It is reported that the body length is a key indicator of embryo development, and nutrient losses can result in a shorter body length. Since the yolk sac is an embryo's only source of nutrition, it plays an important role during the early stages of development, and its physical size decreases as the embryo develops. (Zhang et al. 2015). Cephalosporin $C(C P C)$ is a fungus-derived metabolite that is used to make 7-amino cephalosporanic acid (7-ACA) (Das et al. 2019). This noxious cephalosporin derived 7-amino cephalosporanic acid (7-ACA) affects Zebra fish embryos during organogenesis in aqueous medium. Finally, it produces developmental toxicity, resulting in morphological malformations . C3 and C7 are cephalosporin substituents that are much more poisonous than 7-ACA (Zhang et al. 2015). The toxicity of C3 and C7 may be exerted individually or in a synergistic manner. It is also reported that toxicity is also caused by the N-methylthiotetrazole (MTT) ring, which is a C3 substituent of cephalosporin and induces haemorrhage and hypoprothrombinemia by causing vitamin $\mathrm{K}$ deficciency and inhibiting aldehyde dehydrogenase. Platelet dysfunction is caused by the - $\mathrm{COO}$ group, which is present at $\mathrm{C} 7$ location. The role of genes, proteins, and biomarkers in the toxicity process is unknown at this time (Das et al. 2019) .

In our present study, 7-ACA, C3 and C7 may present in CEFTR that slowed the absorption of the yolk sac and causes zebrafish embryos to mature more slowly. This constituents may responsible for CEFTRinduced developmental toxicity in zebrafish embryos.

The findings of our current research are close to those previously published. After a brief exposure period, erythromycin, lincomycin, and ibuprofen cause DNA damage (Rocco et al. 2012). CEFTR raises the tail moment substantially, according to a new analysis (Fig. 4b). After a short time exposure, atorvastatin and gemfibrozil confirm a clear DNA damage, according to the study. Some antibiotics have been confirmed to cause a significant increase in DNA migration (tail moment). As a result, these drugs are a pollutant to the environment. (Rocco et al. 2012). Cephalosporin is said to damage DNA by breaking DNA strands. The oxidized guanine residues are incorporated into the genome (Shapiro 2015). CEFT is the cephalosporin drug. In our study,it is confirmed that CEFTR causes DNA damage. From the previous 
report, it is explained that intermediated product present in CEFTR damage DNA by breaking DNA strands and incorporating guanine residue in the genome.

However, since antibiotic residues have not been reported in the past, our recent study may be the first to show that antibiotic residues cause DNA damage. This may reports first time that DNA damage occurred by antibiotic residue like CEFTR.

In our study, CEFTR affect on body length and yolk sack area. 7-ACA, C3 and C7 are the constituents of CEFTR, have an impact on the zebra fish embryo in the stage of development.. CEFTR also boosts the percentage of tail DNA and the tail moment by breaking DNA strands and incorporating guanine residue in the genome that ultimately damages DNA. Our findings showed that the antibiotic could have a successful therapeutic application with a low risk of drug residue in milk, which could aid in the rational selection of antibiotics for the treatment of mastitis without causing residue in the food chain. Long-term investigations with several antibiotics and more cow herds are needed for this research.

\section{Declarations}

Ethics approval and consent to participate: All authors have the ethics to publish this manuscript

Availability of data and materials: All authors have agreed to make data and materials accessible.

Competing interest: There are no conflicting interests declared by the authors.

Consent for publication: The publication of this paper was approved by all of the authors.

Funding: This research does not have any funding sources

\section{Author's contribution}

JC: Data Curation, Methodology, Validation, Writing Original draft, \& Editing; RM and DD: Methodology; TKM: Resources, Project Supervision; TB*: Methodology, Resources , Project Supervision; SM*: Conceptualization, Methodology, Investigation, Data Curation, Project Supervision, Writing - Original Draft, Review \& Editing.

\section{Acknowledgments:}

The authors express their gratitude to the Chancellor of Techno India University, West Bengal for providing the requisite laboratory and infrastructural support.

\section{References}

Aalipour F, Mirlohi M, Jalali M, Azadbakht L (2015) Dietary exposure to tetracycline residues through milk consumption in Iran. J Environ Health Sci Eng 13:80. https://doi.org/10.1186/s40201-015-0235-6 
Beyene T (2015) Veterinary Drug Residues in Food-animal Products: Its Risk Factors and Potential Effects on Public Health. J Vet Sci Technol 07: https://doi.org/10.4172/2157-7579.1000285

Bhat AM, Soodan JS, Singh R, et al (2017) Incidence of bovine clinical mastitis in Jammu region and antibiogram of isolated pathogens. Vet World 10:984-989. https://doi.org/10.14202/vetworld.2017.984989

Cháfer-Pericás C, Maquieira Á, Puchades R (2010) Fast screening methods to detect antibiotic residues in food samples. TrAC Trends Anal Chem 29:1038-1049. https://doi.org/10.1016/j.trac.2010.06.004

Chowdhury J, Mandal TK, Mondal S (2020) Genotoxic impact of emerging contaminant amoxicillin residue on zebra fish (Danio rerio) embryos. Heliyon 6:e05379.

https://doi.org/10.1016/j.heliyon.2020.e05379

Das N, Madhavan J, Selvi A, Das D (2019) An overview of cephalosporin antibiotics as emerging contaminants: a serious environmental concern. 3 Biotech 9:231. https://doi.org/10.1007/s13205-019$1766-9$

D'Costa AH, Shyama SK, Praveen Kumar MK, Fernandes TM (2018) Induction of DNA damage in the peripheral blood of zebrafish (Danio rerio) by an agricultural organophosphate pesticide, monocrotophos. Int Aquat Res 10:243-251. https://doi.org/10.1007/s40071-018-0201-x

Diwan V, Hanna N, Purohit M, et al (2018) Seasonal Variations in Water-Quality, Antibiotic Residues, Resistant Bacteria and Antibiotic Resistance Genes of Escherichia coli Isolates from Water and Sediments of the Kshipra River in Central India. Int J Environ Res Public Health 15:1281. https://doi.org/10.3390/ijerph15061281

Elizalde-Velázquez A, Gómez-Oliván LM, Galar-Martínez M, et al (2016) Amoxicillin in the Aquatic Environment, Its Fate and Environmental Risk. In: Larramendy M, Soloneski S (eds) Environmental Health Risk - Hazardous Factors to Living Species. InTech

Feng L, Cheng Y, Zhang Y, et al (2020) Distribution and human health risk assessment of antibiotic residues in large-scale drinking water sources in Chongqing area of the Yangtze River. Environ Res 185:109386. https://doi.org/10.1016/j.envres.2020.109386

Frenzilli G, Lenzi P, Scarcelli V, et al (2004) Effects of loud noise exposure on DNA integrity in rat adrenal gland. Environ Health Perspect 112:1671-1672. https://doi.org/10.1289/ehp.7249

Graham JP, Boland JJ, Silbergeld E (2007) Growth Promoting Antibiotics in Food Animal Production: An Economic Analysis. Public Health Rep 122:79-87. https://doi.org/10.1177/003335490712200111

Hassan MM (2014) Antimicrobial Resistance Pattern against E. coli and Salmonella in Layer Poultry. Res J Vet Pract 2:30-35. https://doi.org/10.14737/journal.rjvp/2014/2.2.30.35 
Ibrahim FA, Nasr JJM (2014) Direct determination of ampicillin and amoxicillin residues in food samples after aqueous SDS extraction by micellar liquid chromatography with UV detection. Anal Methods 6:1523. https://doi.org/10.1039/c3ay42011f

Kraemer SA, Ramachandran A, Perron GG (2019) Antibiotic Pollution in the Environment: From Microbial Ecology to Public Policy. Microorganisms 7:180. https://doi.org/10.3390/microorganisms7060180

Kurjogi M, Issa Mohammad YH, Alghamdi S, et al (2019) Detection and determination of stability of the antibiotic residues in cow's milk. PLOS ONE 14:e0223475. https://doi.org/10.1371/journal.pone.0223475

Meletiadis J, Turlej-Rogacka A, Lerner A, et al (2017) Amplification of Antimicrobial Resistance in Gut Flora of Patients Treated with Ceftriaxone. Antimicrob Agents Chemother 61:e00473-17, e00473-17. https://doi.org/10.1128/AAC.00473-17

Mpatswenumugabo JP, Bebora LC, Gitao GC, et al (2017) Prevalence of Subclinical Mastitis and Distribution of Pathogens in Dairy Farms of Rubavu and Nyabihu Districts, Rwanda. J Vet Med 2017:1-8. https://doi.org/10.1155/2017/8456713

Nisha A (2008) Antibiotic Residues - A Global Health Hazard. Vet World 2:375. https://doi.org/10.5455/vetworld.2008.375-377

Nishimura Y, Inoue A, Sasagawa S, et al (2016) Using zebrafish in systems toxicology for developmental toxicity testing: Zebrafish and developmental toxicity. Congenit Anom 56:18-27. https://doi.org/10.1111/cga.12142

Olive PL, Durand RE (2005) Heterogeneity in DNA damage using the comet assay. Cytom Part J Int Soc Anal Cytol 66:1-8. https://doi.org/10.1002/cyto.a.20154

Oliveira R, McDonough S, Ladewig JCL, et al (2013) Effects of oxytetracycline and amoxicillin on development and biomarkers activities of zebrafish (Danio rerio). Environ Toxicol Pharmacol 36:903912. https://doi.org/10.1016/j.etap.2013.07.019

Ostling O, Johanson KJ (1984) Microelectrophoretic study of radiation-induced DNA damages in individual mammalian cells. Biochem Biophys Res Commun 123:291-298.

https://doi.org/10.1016/0006-291x(84)90411-x

Ray P, Knowlton KF, Shang C, Xia K (2014) Development and Validation of a UPLC-MS/MS Method to Monitor Cephapirin Excretion in Dairy Cows following Intramammary Infusion. PLoS ONE 9:e112343. https://doi.org/10.1371/journal.pone.0112343

Rocco L, Peluso C, Stingo V (2012) Micronucleus test and comet assay for the evaluation of zebrafish genomic damage induced by erythromycin and lincomycin. Environ Toxicol 27:598-604. https://doi.org/10.1002/tox.20685 
Ruegg PL (2017) A 100-Year Review: Mastitis detection, management, and prevention. J Dairy Sci 100:10381-10397. https://doi.org/10.3168/jds.2017-13023

Sachi S, Ferdous J, Sikder M, Hussani S (2019) Antibiotic residues in milk: Past, present, and future. J Adv Vet Anim Res 6:315. https://doi.org/10.5455/javar.2019.f350

Schenck FJ, Callery PS (1998) Chromatographic methods of analysis of antibiotics in milk. J Chromatogr A 812:99-109. https://doi.org/10.1016/s0021-9673(97)01291-0

Seymour EH, Jones GM, McGilliard ML (1988) Persistence of residues in milk following antibiotic treatment of dairy cattle. J Dairy Sci 71:2292-2296. https://doi.org/10.3168/jds.S0022-0302(88)79806-9

Shapiro RS (2015) Antimicrobial-Induced DNA Damage and Genomic Instability in Microbial Pathogens. PLOS Pathog 11:e1004678. https://doi.org/10.1371/journal.ppat.1004678

Sileshi A, Tenna A, Feyissa M, Shibeshi W (2016) Evaluation of ceftriaxone utilization in medical and emergency wards of Tikur Anbessa specialized hospital: a prospective cross-sectional study. BMC Pharmacol Toxicol 17:7. https://doi.org/10.1186/s40360-016-0057-x

Singh NP, McCoy MT, Tice RR, Schneider EL (1988) A simple technique for quantitation of low levels of DNA damage in individual cells. Exp Cell Res 175:184-191. https://doi.org/10.1016/00144827(88) $90265-0$

Sonda TB, Horumpende PG, Kumburu HH, et al (2019) Ceftriaxone use in a tertiary care hospital in Kilimanjaro, Tanzania: A need for a hospital antibiotic stewardship programme. PLOS ONE 14:e0220261. https://doi.org/10.1371/journal.pone.0220261

Speit G, Rothfuss A (2012) The comet assay: a sensitive genotoxicity test for the detection of DNA damage and repair. Methods Mol Biol Clifton NJ 920:79-90. https://doi.org/10.1007/978-1-61779-9983_6

Teuber M (2001) Veterinary use and antibiotic resistance. Curr Opin Microbiol 4:493-499. https://doi.org/10.1016/s1369-5274(00)00241-1

Van den Meersche T, Pamel EV, Poucke CV, et al (2016) Development, validation and application of an ultra high performance liquid chromatographic-tandem mass spectrometric method for the simultaneous detection and quantification of five different classes of veterinary antibiotics in swine manure. $J$ Chromatogr A 1429:248-257. https://doi.org/10.1016/j.chroma.2015.12.046

Ying G-G, He L-Y, Ying AJ, et al (2017) China Must Reduce Its Antibiotic Use. Environ Sci Technol 51:1072-1073. https://doi.org/10.1021/acs.est.6b06424

Zhang Q, Cheng J, Xin Q (2015) Effects of tetracycline on developmental toxicity and molecular responses in zebrafish (Danio rerio) embryos. Ecotoxicology 24:707-719. 
Zhao Y, Liang X, Wang Y, et al (2018) Degradation and removal of Ceftriaxone sodium in aquatic environment with Bi2WO6/g-C3N4 photocatalyst. J Colloid Interface Sci 523:7-17.

https://doi.org/10.1016/j.jcis.2018.03.078

\section{Figures}

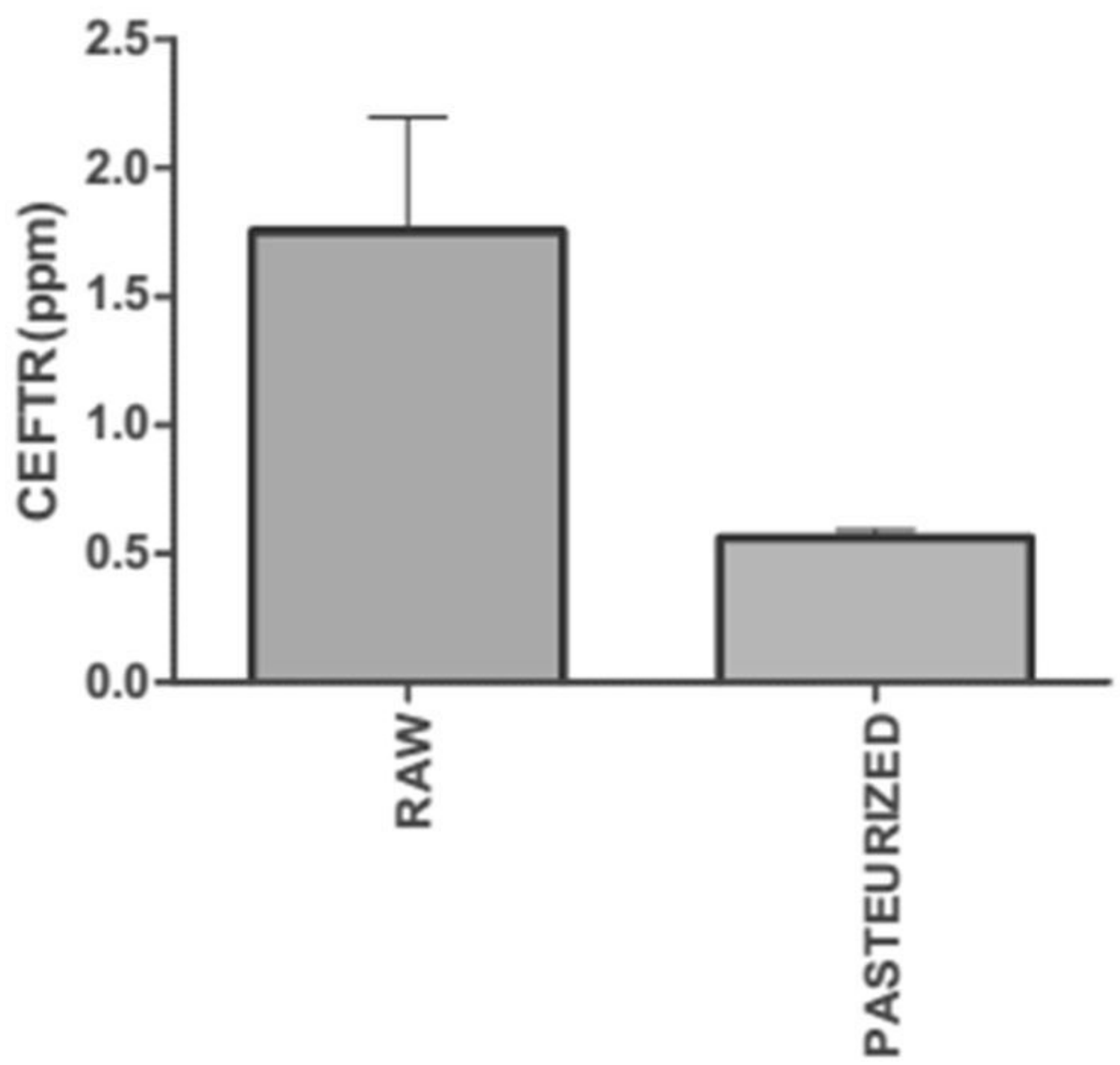

\section{Figure 1}

Concentration of Ceftriaxone residue (CEFTR) in raw and pasteurized mastitis cow milk determined by using high-performance liquid chromatography (HPLC). These experiments were performed for three 
times with three sets. The data are shown as average values \pm SD. P $₫ 0.05$ defines significant difference of concentration between raw milk and pasteurized milk
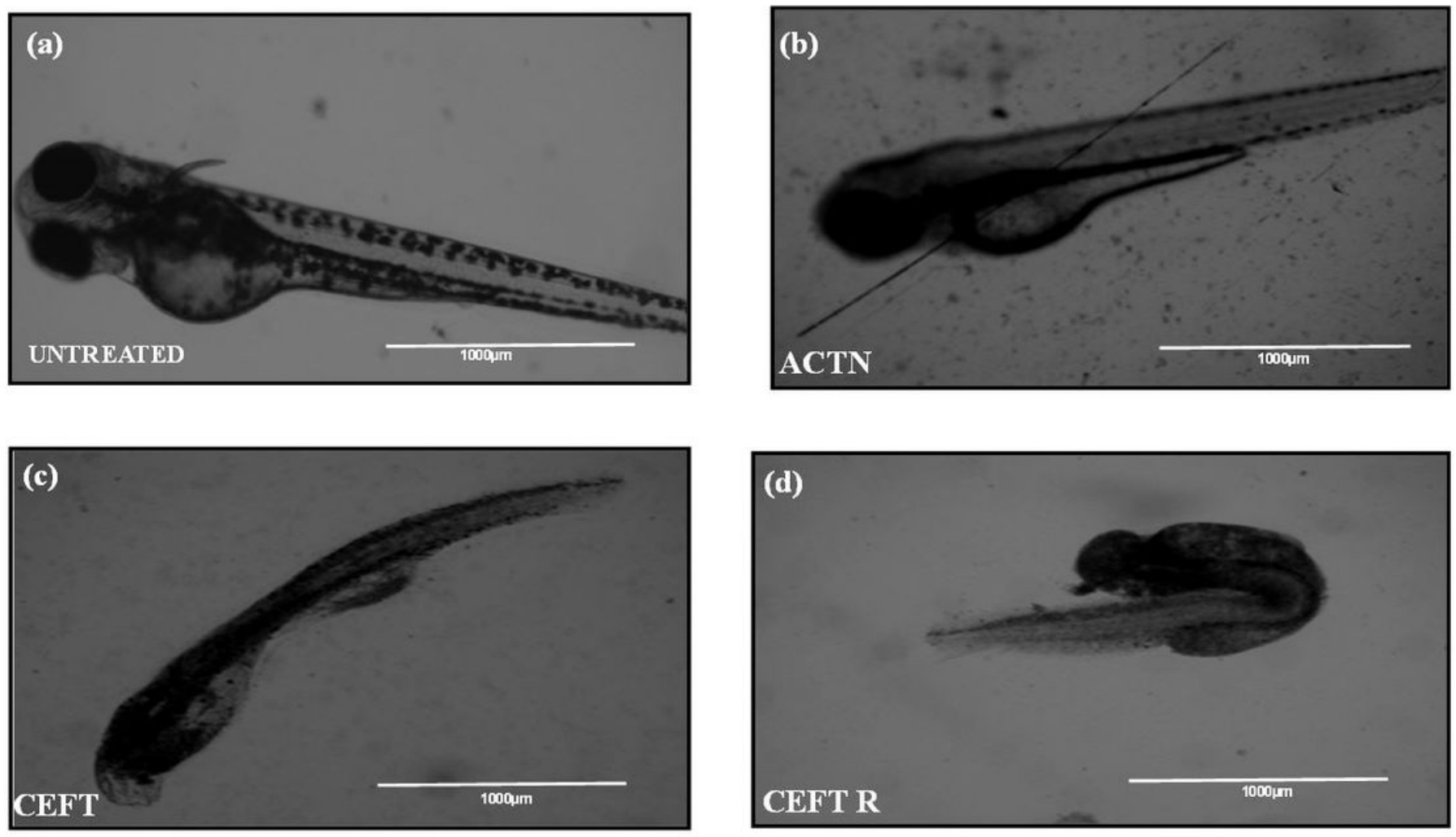

\section{Figure 2}

(a) Image of untreated D. rerio embryos at $72 \mathrm{hpf}$. (b)Image of D. rerio embryos malformations after ACTN treatment at $72 \mathrm{hpf}$ (c) Image of D. rerio embryos malformations after CEFT treatment at $72 \mathrm{hpf}$ (d) Image of D. rerio embryos malformations after CEFTR treatment at $72 \mathrm{hpf}$. 
(a)

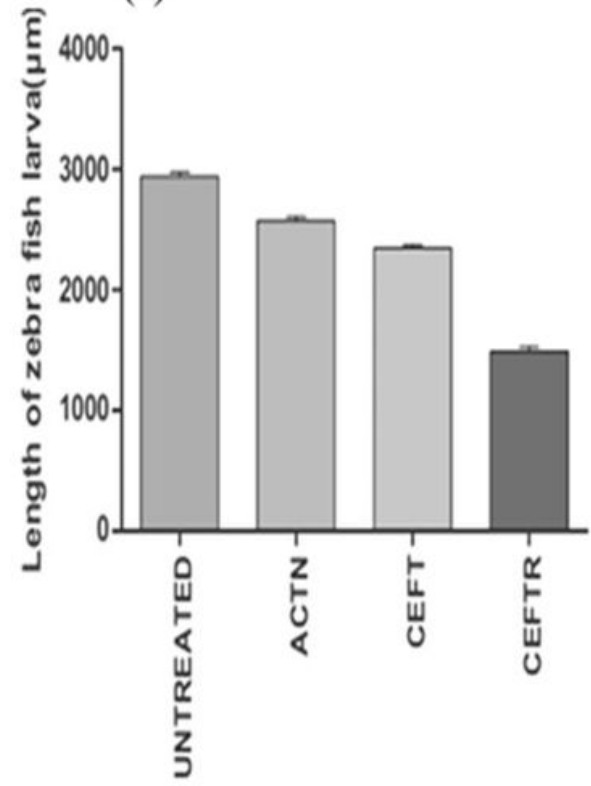

(b)

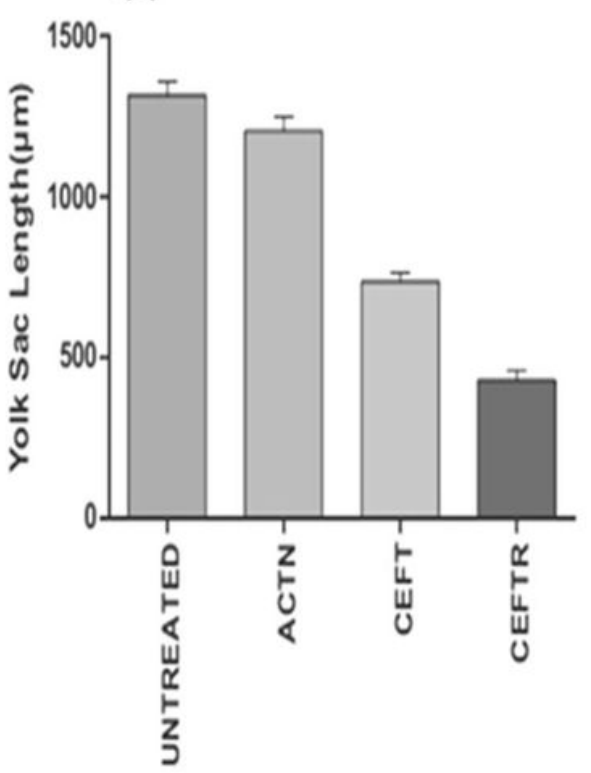

(c)

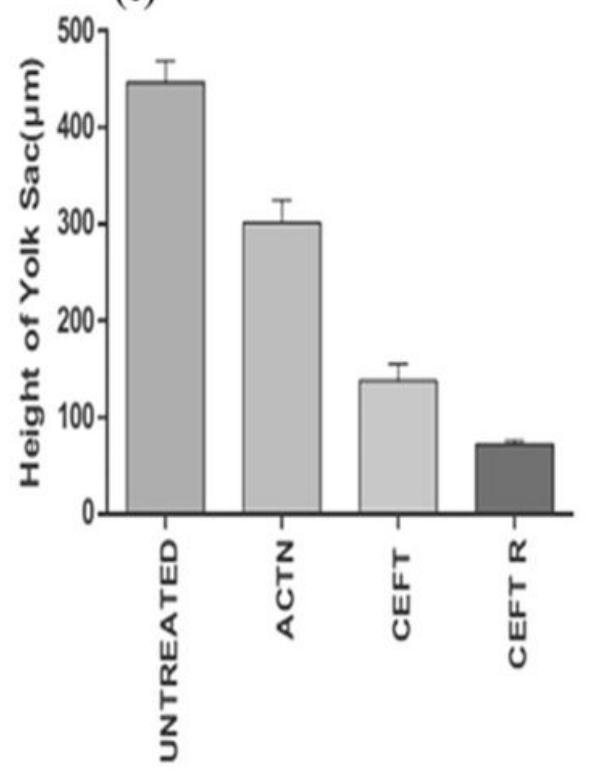

\section{Figure 3}

(a) Body length of D. rerio embryos without treatment (untreated) and with treatment of ACTN, CEFT and CEFTR at $72 \mathrm{hpf}$ (b) Length of yolk sac of D. rerio embryos without treatment (untreated) and with treatment of ACTN, CEFT and CEFTR at $72 \mathrm{hpf}$.(c) Height of yolk sac of D. rerio embryos without treatment (untreated) and with treatment of ACTN, CEFT and CEFTR at $72 \mathrm{hpf}$
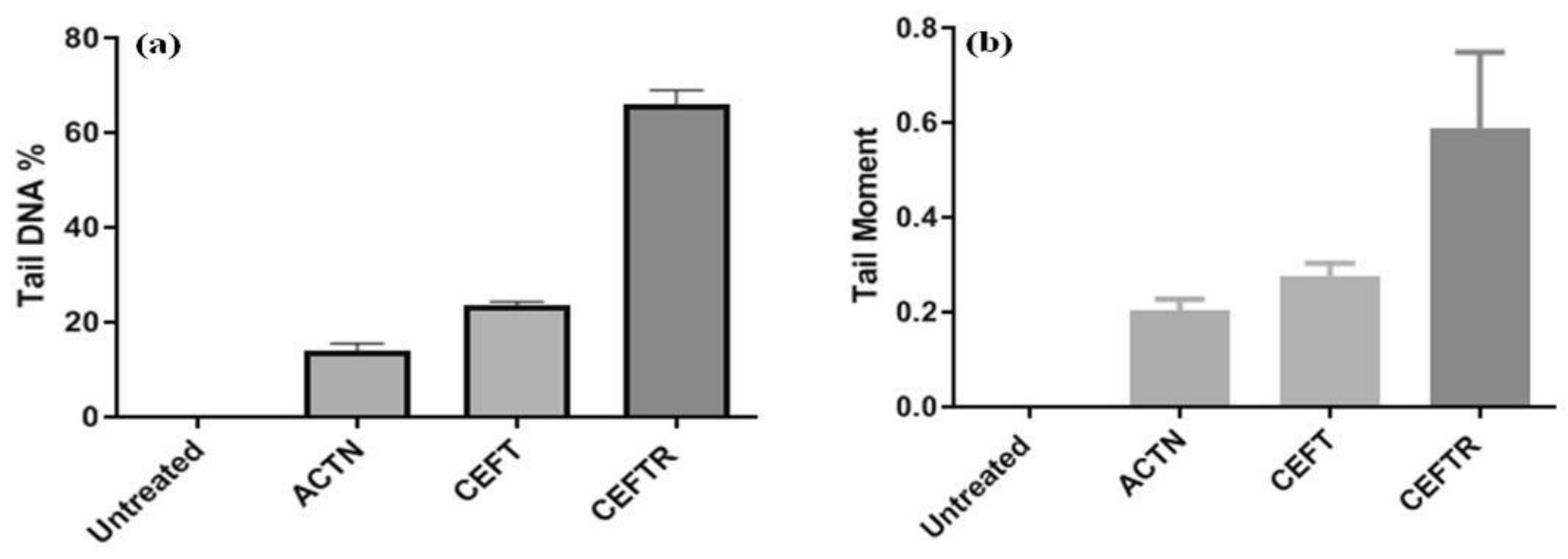

Figure 4

(a) Tail DNA (\%) in cells of D. rerio without treatment (Untreated) and treatment with ACTN, CEFT and CEFTR at 48hpf (b) Tail DNA moment in cells of D. rerio without treatment (Untreated) and treatment with 
ACTN, CEFT and CEFTR at 48hpf

Page 15/15 